\title{
COMPARISON OF TWO METHODS FOR SAMPLING THRIPS IN NECTARINES IN SPRING
}

\author{
P.L. $\mathrm{LO}^{1}$ and G.F. McLAREN ${ }^{2}$ \\ ${ }^{1}$ HortResearch, Hawke's Bay Research Centre, Private Bag 1401, Havelock \\ North, New Zealand \\ ${ }^{2}$ HortResearch, Clyde Research Centre, R.D. 1 Alexandra, Central Otago, New \\ Zealand
}

Corresponding author: plo@hortresearch.co.nz

\begin{abstract}
Thrips were sampled by tapping 200 nectarine branches and collecting dislodged insects on a plate, or by picking 200 flowers (or fruitlets postflower) and passively extracting thrips using heat. Both methods were tested in various weather conditions and at different times of day. More thrips were collected by tapping branches than picking flowers/fruitlets, particularly post-flowering. However, catches from tapping were greatly influenced by wind speed; temperature had less effect than wind. Picking flowers gave more consistent results during bloom than tapping branches and also collected larvae. The age of flowers and their aspect on the tree did not affect catches. Tapping branches was the better method for export crops where sampling needs to continue after petal fall. The picking method is suitable where there is a greater tolerance for thrips damage, such as fruit destined for the domestic market.
\end{abstract}

Keywords: thrips, sampling, stonefruit, integrated fruit production, monitoring.

\section{INTRODUCTION}

Thrips (Thysanoptera: Thripidae) are one of the main pests of nectarine (Prunus persica) in New Zealand. In spring, nectarines are susceptible to damage by thrips for about 7 weeks from flowering to shuck fall. Thrips feeding in flowers damage the developing fruitlets and the resultant scarring develops into blocks and lines of russet, accompanied by distorted colour patterns and a roughened fruit surface. Although fruitlets are less susceptible to damage after petal fall, this is offset by higher numbers of thrips associated with the emergence of a second generation (McLaren \& Fraser 2000). The two main pest species are New Zealand flower thrips (NZFT, Thrips obscuratus) and onion thrips (Thrips tabaci), which causes less damage (McLaren 1992).

There are four main methods used to sample thrips: tapping branches (McLaren \& Fraser 2000), sticky traps and suction traps (McLaren 1995), and flicking flowers (Bradley \& Mayer 1994). These methods are simple to use, but each has significant drawbacks. Tapping can sample a large number of flowers and leaves, and gives an instant result. However, it is difficult to standardise and results depend on weather conditions at the time of sampling. This method is used to monitor thrips in the New Zealand SummerGreen (integrated fruit production) programme. It is used in conjunction with a three-stage spray threshold from bloom to shuck fall (McLaren \& Fraser 2000). Sticky traps give a continuous sample of thrips activity but are messy, require expert identification of thrips and catches vary depending on their location in relation to shelter and wind direction. Finger flicks similarly can give variable results. Suction traps can be used to monitor activity hourly or daily (McLaren 1995), but the equipment is not readily available to growers. Additionally, suction trap catches need to be identified and counted under a microscope. 
Ideally, a monitoring method is needed that is not dependent on the weather or time of day, and that is simple for growers to use. It should also be easy to standardise and give consistent results. Preliminary results from assessing alternative methods of sampling thrips suggested that picking flowers and using heat to passively extract thrips could fulfil these criteria. This paper compares this method with the standard technique of tapping branches for monitoring thrips in spring.

\section{Thrips sampling}

\section{METHODS}

In Hawke's Bay sampling was conducted at two orchards from 17-26 September 2001, and 10 orchards between 10 September and 11 October 2002. In Central Otago one block at the HortResearch Clyde Research Station was sampled between 20 September and 3 November 2000, and 12-24 October 2001.

Branch tapping method: At each sample time, 200 branches (approximately $2-3 \mathrm{~cm}$ diameter) were tapped from 10 (Central Otago) or 40-50 (Hawke's Bay) trees. A $25 \mathrm{~cm}$ diameter yellow plastic plate was held underneath the selected branch, while the branch was tapped sharply once, using a rubber or Velcro®-covered iron pipe. The plate was held as close as possible to the flowers and checked for thrips after every 5 taps. The branches sampled were 1-1.5 m above ground level, covering all aspects of the tree. On one occasion in Central Otago the number of blossoms on each sampled branch was counted and the proportion of each tree sampled was estimated.

Flower picking method: At each sample time, 200-400 open flowers (one/shoot) were randomly sampled up to the "burst calyx" stage. Between then and "shuck fall" (fruits swelled and calyx shed), 15 shoots with approximately six fruits/shoot were sampled each time. The thrips extraction efficiency of two methods was tested from two samples. Each time half the flowers were kept in closed plastic bags and half put in funnels fitted with wire mesh across the neck to prevent clogging. Heat was applied via a $100 \mathrm{~W}$ desk lamp placed over the funnels to drive thrips down into pottles containing water and a drop of detergent. Another lamp was positioned over one end of the plastic bags to drive thrips to the cooler end. After 2 hours the flowers in the funnels and bags were pulled apart to check how many thrips had not been extracted.

Thrips species: A sub-sample of thrips was collected in ethanol and identified using the key of Mound \& Walker (1982).

\section{Comparisons between sampling methods}

The effect of four factors on the numbers of thrips collected by the two methods was evaluated. All factors were tested in Hawke's Bay and only the flower stage factor tested in Central Otago.

Stage of flowering: The number of larvae and adults per sample, and the time taken to conduct the sampling during flowering and after "petal fall" were recorded.

Time of day: On eight occasions in Hawke's Bay thrips were sampled three times on the same day: morning (0830-0930), midday (1200-1300) and afternoon (1530-1630). Samples were collected from three orchards.

Air temperature and wind speed: These factors were recorded by the automatic weather station at HortResearch, Havelock North, which was within $6 \mathrm{~km}$ of all the orchards sampled. The temperature was taken at the start of the sampling period, while wind speed was the average for the hour in which sampling was conducted.

The picking method was tested further on four Hawke's Bay orchards to determine whether the age of flowers or their aspect on the tree affected numbers of thrips collected.

Flower age: Fifty nectarine cv. Fantasia flowers per sample were picked at each of the following four stages: (i) "popcorn" (not quite or just open), (ii) newly opened (with pale pink petals and stamens), (iii) mature (with dark pink petals and stamens) and (iv) "petal fall" (most or all petals gone).

Aspect on tree: Fifty flowers were sampled from each of the four quadrants of the trees. 


\section{Data analysis}

Comparisons between the number of thrips recorded by tapping branches or picking flowers were analysed by paired-sample $t$ tests. Thrips abundance during and after flowering was compared by two-sample $t$ tests. Where significant $(\mathrm{P}<0.05)$ differences between means occurred, a Fisher's least significant difference (LSD) test was performed. Samples taken at different times of day were compared by one-way ANOVA. Samples of different flower age and aspect were analysed by chi-square.

\section{Thrips recovery from flower samples}

\section{RESULTS}

A $93 \%(n=30)$ and $87 \%(n=23)$ recovery of adults and larvae respectively was achieved with the funnels, compared with $55 \%(n=40)$ and $0 \%(n=4)$ in the bags. Based on these results funnels were used thereafter.

\section{Thrips species}

Samples in Hawke's Bay had $14 \%$ NZFT and $80 \%$ onion thrips $(n=70)$. In Central Otago, the species comprised $96 \%$ NZFT and the predatory Haplothrips kurdjumovi $4 \%$ $(\mathrm{n}=113)$.

\section{Stage of flowering}

Tapping 200 branches before and after "petal fall" indicated that: (i) this method collected more adult thrips than picking 200 flowers and (ii) thrips abundance on trees was similar in both periods (Table 1). In contrast, the picking method recorded more thrips from flowers than fruitlets in Hawke's Bay. In Hawke's Bay, larvae were found in flowers and fruitlets (mean 4.2 and 4.3/sample respectively), but not by tapping branches. No larvae were found in samples from Central Otago. In Central Otago, it was estimated that tapping 200 branches sampled about 1600 flowers and $44 \%$ of the tree.

TABLE 1: Mean number of New Zealand flower thrips and onion thrips per sample collected before and after petal fall by tapping 200 branches or picking 200 flowers or 200 fruitlets.

\begin{tabular}{lcclcc}
\hline & No. samples & Tapping & Picking & P value & LSD $(\mathrm{P}<0.05)$ \\
\hline Hawke's Bay & & & & & \\
$\quad$ Flowering & 32 & 37.1 & 6.9 & $<0.001$ & 5.2 \\
$\quad$ Petal fall to Shuck fall & 3 & 30.0 & 0.7 & 0.165 & - \\
$\quad$ P value & & 0.480 & 0.016 & & \\
$\quad$ LSD (P<0.05) & & - & 5.0 & & \\
& & & & & \\
Central Otago & 4 & 10.0 & 5.6 & 0.037 & 3.9 \\
$\quad$ Flowering & 5 & 12.8 & 2.1 & $<0.001$ & 2.1 \\
$\quad$ Petal fall to Shuck fall & 5 & 0.253 & 0.178 & & \\
$\quad$ P value & & - & - & & \\
$\quad$ LSD $(\mathrm{P}<0.05)$ & & & &
\end{tabular}

\section{Time of day}

Similar numbers of adult thrips were collected at the morning, midday and afternoon sampling times by tapping (means of $36.4,33.6$ and 44.0 thrips respectively, $\mathrm{P}=0.46$ ), and by picking flowers (means $6.5,6.5$ and 7.4 respectively, $\mathrm{P}=0.86$ ).

\section{Wind}

In Hawke's Bay, wind speed had a large effect on numbers of thrips collected by tapping, but not by picking flowers (Fig. 1). For example, the regression equation estimated that in nearly calm conditions $(3 \mathrm{~km} / \mathrm{h})$, tapping would produce on average 49 thrips per sample, but just 18 when it was windy $(27 \mathrm{~km} / \mathrm{h})$. In contrast, numbers of thrips in flowers were virtually unchanged (6-7 per sample) over the whole range of wind speeds encountered. 


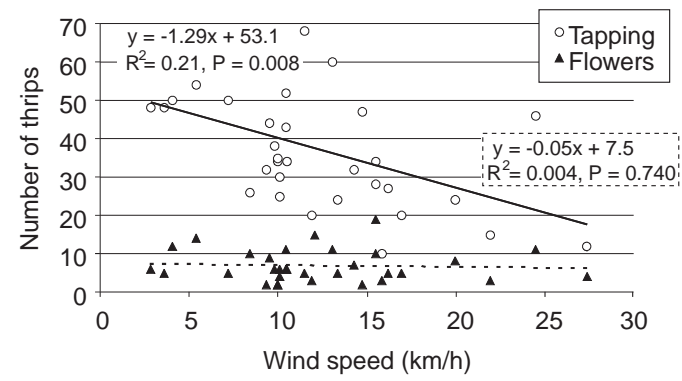

FIGURE 1: Plot of wind speed versus number of thrips per sample from tapping 200 branches or picking 200 flowers $(n=32)$.

\section{Temperature}

Sampling in Hawke's Bay was conducted at temperatures from $9-23^{\circ} \mathrm{C}$. Both methods had inverse trends between temperature and numbers of thrips (Fig. 2).

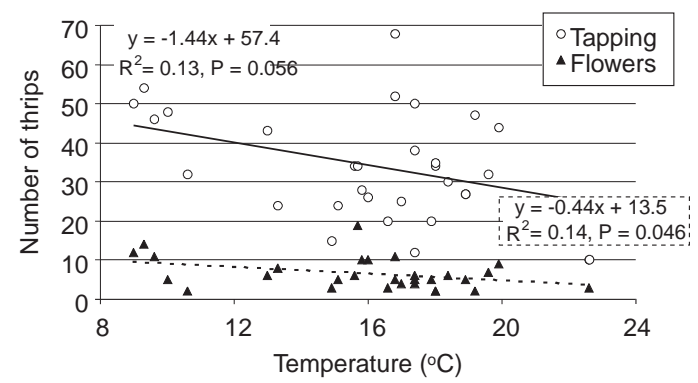

FIGURE 2: Plot of temperature versus number of thrips per sample from tapping 200 branches or picking 200 flowers $(n=29)$.

\section{Age of flowers and aspect}

Neither the age of flowers nor the aspect of the tree on which they were located influenced the numbers of adult thrips collected in Hawke's Bay (data not shown). The numbers of larvae collected were similarly unaffected by the age of the flowers, but more larvae were found on the southern aspect of trees than the north (46 versus 15 from 20 samples, $\mathrm{P}<0.001$ ).

\section{DISCUSSION}

The main advantage of the tapping method over picking flowers was that it collected more thrips both during and after flowering. Because tapping branches sampled from leaves, wood and flowers, it yielded more thrips in the same sampling time than picking flowers, even though the latter method collected more thrips per flower. The two methods were similar in terms of the time and effort involved in sampling. Tapping branches took about 30 minutes per sample in Hawke's Bay compared with 15 minutes in Central Otago. The difference was partly due to the size of trees sampled. On large trees in Otago 10 taps were made on 20 trees, whereas in Hawke's Bay up to 50 smaller trees were used, which involved more walking. At both sites, it took 25-30 minutes to pick 200 flowers and process them in the laboratory.

A key advantage of the flower picking method was that it produced more consistent results in different weather conditions. Catches of thrips in flowers were unaffected by 
wind, whereas even a breeze reduced numbers on the yellow plate. Two factors could explain the variable results from tapping in different wind strengths. Firstly, thrips tend to withdraw into crevices when relative humidity falls, as is common in windy conditions. If strong wind makes thrips shelter inside the calyx (shuck) or new leaf shoots, this could make them more difficult to dislodge. Secondly, with tapping, an unknown proportion of the falling thrips could miss the plate. This proportion could vary greatly between samples conducted in different winds. Because the spray threshold for export crops over flowering is only five thrips per 200 taps (McLaren \& Fraser 2000), it is important to catch every thrips, or at least a constant proportion of those dislodged.

Another advantage of picking flowers was that it is easily standardised between different scouts and orchards. In comparison, the tapping technique is open to interpretation in several areas. For example, the size of branch, number of flowers included and strength of tapping will affect the numbers of thrips dislodged. Unless the sampled branches are at the same angle, the collecting plate must be held at varying distances below the flowers, which is likely to affect the proportion of thrips collected. However, for the picking method to be used as a monitoring tool, either new thresholds are needed in the SummerGreen programme, or the sample size has to be increased. For example, to collect an equivalent number of thrips as tapping branches, samples of 200 or 1000 flowers would be needed in Central Otago and Hawke's Bay respectively. This would take considerably longer than tapping 200 branches and consequently would be unpopular with growers.

For both methods, catches of thrips were unaffected by the daily time of sampling. McLaren \& Fraser (2002) had similar results when tapping from the ground, although catches dropped around 1700 hours. They found a different situation in the top of trees, where numbers of thrips declined by half between samples taken at 0900 hours and those at 1700 hours. These diurnal patterns of thrips abundance in trees correlated poorly with the activity of NZFT measured by suction traps, which catch flying insects. Suction traps caught most thrips during the warmest part of the day, between 1000-1500 hours (McLaren 1995). In the current study thrips were sampled directly from trees and it was found that temperature had a smaller but opposite effect. The abundance of adult thrips was unaffected by the within-tree aspect for both flowers (this study) and tapping (McLaren \& Fraser 2002). In this study tapping dislodged only adult thrips, although McLaren and Fraser (2000) did record larvae using this method.

Tapping branches is the preferred method in Central Otago where sampling needs to continue until "shuck fall" to monitor the risk of damage from the second generation of NZFT. Tapping also gives early warning of the presence of green peach aphid (Myzus persicae), several weeks before symptoms of curled leaves appear. Because the most critical variable affecting this method was wind speed, it is more important to sample in calm conditions than at a particular time of day. However, avoiding late afternoon sampling is recommended.

The flower picking method can be used on all ages of flowers up to "petal fall" and in a wider range of conditions than tapping. It is well suited to situations like Hawke's Bay where most of the crop goes to the domestic market. The greater tolerance for thrips damage on fruit destined for the local market compared to export crops, means growers are mainly concerned with monitoring during the prime susceptible period of bloom. Also because a higher spray threshold is feasible in Hawke's Bay, the sample size can be kept at a practical number of flowers.

\section{ACKNOWLEDGEMENTS}

We thank Lyn Cole, Jenny Fraser and Ingrid Moen for technical help, and the growers who gave us access to their orchards. Comments by Dr Nigel Bell improved the manuscript. Funding was provided by the Foundation for Research, Science and Technology, and Summerfruit New Zealand. 


\section{REFERENCES}

Bradley, S.J.; Mayer, D.F. 1994: Evaluation of monitoring methods for western flower thrips, Frankliniella occidentalis (Thysanoptera: Thripidae), during the blossom period of 'Granny Smith' apples. J. Entomol. Soc. British Columbia 91: 63-68.

McLaren, G.F. 1992: Thrips on nectarines in spring. Proc. $45^{\text {th }}$ N.Z. Plant Prot. Conf.: 111-115.

McLaren, G.F. 1995: Factors influencing the monitoring of New Zealand flower thrips Thrips obscuratus (Crawford). Proc. Australia and New Zealand Thrips workshop: methods biology, ecology and management. Gosford, Australia. Pp. 52-62.

McLaren, G.F.; Fraser, J.A. 2000: Development of thresholds for insecticidal control of New Zealand flower thrips on nectarines in spring. N.Z. Plant Prot. 53: 194-199.

McLaren, G.F.; Fraser, J.A. 2002: Diurnal activity of New Zealand flower thrips on stonefruit in spring and at harvest. Proc. $7^{\text {th }}$ International Symposium on Thysanoptera: 269-271.

Mound, L.A.; Walker, A.K. 1982: Terebrantia (Insecta: Thysanoptera). Fauna of New Zealand 1. DSIR Publishing, Wellington. 113 p. 